\title{
Compared optical performances of multifocal and monofocal intraocular lenses (contrast sensitivity and dynamic visual acuity)
}

\author{
W Williamson, L Poirier, P Coulon, Ph Verin
}

The functional results (contrast sensitivity and dynamic visual acuity) of 19 multifocal (3M design) and 14 all polymethylmethacrylate biconvex monofocal intraocular lenses (IOLs), $6 \mathrm{~mm}$ in optical diameter were compared. Best corrected visual acuity was $\geqslant 8 / 10$ (Monoyer chart) Parinaud 2 in all cases. Major differences of functional performance in favour of monofocal IOLs were found outside standard conditions of vision (low contrast and illumination levels). A significant difference in contrast sensitivity was found for each spatial frequency in favour of multifocal IOLs $(0.0016<p<0.05)$. Mesopic vision was statistically higher in the monofocal IOL group $(p=0.0015)$. Moreover, dynamic visual acuity allowed accurate evaluation of the difference in performance between these two models of implant. In view of these results multifocal IOLs should be reserved for patients with normal psychosensitive adaptation; an ocular pathology that could alter contrast sensitivity or mesopic vision is a contraindication for multifocal IOLs.

(Br f Ophthalmol 1994; 78: 249-251)

Multifocal (diffractive) and bifocal (refractive) intraocular lenses (IOLs) are an alternative to monofocal IOLs with a presbiopic correction. The first studies in patients with these IOLs have shown greater patient comfort for near vision without additional extraocular correction. Such optical systems, however, induce aberrations. Some psychophysical tests, such as contrast sensitivity and dynamic visual acuity, make it possible to study these problems.

The aim of this study was to assess these optical aberrations by comparing the functional results (contrast sensitivity and dynamic visual acuity) of monofocal and multifocal IOLs.

\section{Materials and methods}

Centre Jean Abadie Service d'Ophtalmologie du Professeur Verin, 89 rue des Sablières, 33077 Bordeaux Cedex, France W Williamson

L Poirier

PCoulon

Ph Verin

Correspondence to: Dr L Poirier.
Jean Abadie in Bordeaux (France). Nineteen of these eyes received a $3 \mathrm{M}$ type multifocal IOL and 14 had an all polymethylmethacrylate biconvex monofocal IOL, $6 \mathrm{~mm}$ in diameter. All were fitted within the capsular bag. The patients had no other associated ocular pathology.

Group 1 (multifocal IOLs) included 19 eyes from 14 women and four men whose mean age was 73 (range 48-86) years. The time between the operation and the psychophysical tests was 19.5 (range 9-27) months. Thirteen eyes were operated with the manual cataract extracapsular extraction technique and six with the phacoemulsification procedure.

Group 2 (monofocal IOLs) included 14 eyes from five women and five men whose mean age was 73 (range 62-83) years. The time between the surgical intervention and the tests was 19 (range 6-43) months. Ten eyes were operated with the manual cataract extracapsular extraction technique and four with the phacoemulsification technique.

No capsulotomy was performed in any patients during the follow up period.

\section{Methods}

The postoperative functional tests included the following.

\section{Visual acuity (VA)}

We measured the best corrected distant VA (Monoyer's visual acuity chart at 5 metres). The near vision (Parinaud visual acuity chart at 33 centimetres) was measured with and without additional correction.

Contrast sensitivity (CS)

Contrast sensitivity measures the spatial and contrast power of discrimination of the visual system. The apparatus used was a videotest (BVAT II SG, Mentor, LCA). It was composed

Table 1 Clinical data of eyes in groups 1 (multifocal IOLs) and 2 (monofocal IOLs)

\begin{tabular}{|c|c|c|}
\hline & $\begin{array}{l}\text { Group } 1 \\
\text { (multifocal) }\end{array}$ & $\begin{array}{l}\text { Group 2 } \\
\text { (monofocal) }\end{array}$ \\
\hline $\begin{array}{l}\text { Number of eyes } \\
\text { Sex }(\mathrm{F} / \mathrm{M}) \\
\text { Age (years) }\end{array}$ & $\begin{array}{l}19 \\
14 / 4\end{array}$ & $\begin{array}{l}14 \\
5 / 5\end{array}$ \\
\hline $\begin{array}{l}\text { Mean } \\
\text { Range }\end{array}$ & $\begin{array}{l}73 \\
(48-86)\end{array}$ & $\begin{array}{l}73 \\
(62-83)\end{array}$ \\
\hline \multicolumn{3}{|l|}{$\begin{array}{l}\text { Time between operation and } \\
\text { tests (months) }\end{array}$} \\
\hline $\begin{array}{l}\text { Mean } \\
\text { Range }\end{array}$ & $\begin{array}{l}19 \cdot 5 \\
(9-27)\end{array}$ & $\begin{array}{l}19 \\
(6-43)\end{array}$ \\
\hline \multicolumn{3}{|l|}{ Surgical techniques } \\
\hline Manual CEE & 13 & 10 \\
\hline Phaco & & 4 \\
\hline Power of the lens (dioptre) & 18 to $21 \cdot 5$ & 14 to $22 \cdot 5$ \\
\hline \multicolumn{3}{|l|}{$\begin{array}{l}\text { Postoperative astigmatism } \\
\text { (dioptre) }\end{array}$} \\
\hline Mean & $1 \cdot 2$ & $1 \cdot 2$ \\
\hline Range & $(0-3)$ & \\
\hline
\end{tabular}

$\mathrm{CEE}=$ cataract extracapsular extraction

Phaco $=$ phacoemulsification 
of a graphic processor generating a sinusoidal pattern on a screen. The monitor, measuring $26 \times 26$ centimetres representing a visual angle of $4.25^{\circ}$, was placed 3.5 metres away from the patient. The contrast thresholds were recorded by the forced choice method. The patient indicated the pattern orientation, thus validating his answer.

The contrast was diminished progressively until the perception threshold was reached. Five spatial frequencies were tested $-1 \cdot 5,3,6,12,20$ cycles per degree. The mean luminance of the screen was kept unchanged at $85 \mathrm{~cd} / \mathrm{m}^{2}$.

The results were plotted on comparative curves.

\section{Dynamic visual acuity (DVA) ${ }^{2}$}

DVA measures visual acuity at different levels of brightness, taking into consideration the time needed for test perception. The luminance level ranged from superior scotopic $(5 \cdot 8$ logarithmic unit picostilb (LU psb)) to inferior photopic $(8 \cdot 1$ LU psb), so covering the whole mesopic zone where the early photopic deficits were recorded. Measurements were recorded with a modified Goldmann Weeckers adaptometer to which a 25 dioptre negative lens was added, thereby reproducing visual acuities at different levels of luminance. After a 3 minute dark adaptation period, the patient was then preadapted for 5 minutes at $8.5 \mathrm{LU}$ psb. Using a correction for near vision, he was asked to read the tests corresponding to different degrees of visual acuity with a progressively increasing luminance level ranging from $5 \cdot 8$ to $8 \cdot 1 \mathrm{LU}$ psb.

The results were recorded as follows:

- visual acuity (Monoyer's visual acuity chart) as a function of luminance level.

- index $\mathrm{I}=\mathrm{E} \times \mathrm{D} \times \mathrm{A}$

$\mathrm{E}=$ illumination level (LU psb $=$ logarithmic unit picostilb; $10^{8}$ picostilb $=$ $\left.1 \mathrm{~cd} / \mathrm{m}^{2}\right)$.

$\mathrm{D}=$ response delay (in centimal minutes).

$\mathrm{A}=$ angular visual acuity (in centimal minutes of visual acuity angle).

- curves

- for statistical data analysis, the Fisher probability test was used. This test is suitable for small populations (significant if $\mathrm{p} \leqslant 0 \cdot 05$ ).

Table 2 Comparative functional results of multifocal and monofocal IOLs

\begin{tabular}{|c|c|c|}
\hline & $\begin{array}{l}\text { Group I } \\
\text { (multifocal) }\end{array}$ & $\begin{array}{l}\text { Group } 2 \\
\text { (monofocal) }\end{array}$ \\
\hline \multirow[t]{5}{*}{$\begin{array}{l}\text { Best corrected } \\
\text { visual acuity }\end{array}$} & $\begin{array}{l}\text { Distant } 0.8 \text { to } 1.2 \\
\text { near: } \\
\text { without addition }\end{array}$ & \multirow{2}{*}{$\begin{array}{l}\text { Distant } 0.8 \text { to } 1.2 \\
\text { near: } \\
\text { with addition } \\
+3 \text { or }+3 \cdot 50\end{array}$} \\
\hline & P1.5 $\quad 1$ case & \\
\hline & 10 cases & P1.5 4 cases \\
\hline & 5 cases & 10 cases \\
\hline & P4 2 cases & \\
\hline \multicolumn{3}{|c|}{ P2 with addition $(-050 \pm 1 \cdot 25) 7$ cases } \\
\hline \multicolumn{3}{|c|}{ Photopic visual acuity } \\
\hline Mean & \multirow{2}{*}{$\frac{1}{(0 \cdot 5-1 \cdot 2)}$} & \multirow{2}{*}{$\begin{array}{l}1 \\
(0 \cdot 8-1)\end{array}$} \\
\hline Range & & \\
\hline \multicolumn{3}{|c|}{ Mesopic visual acuity } \\
\hline Mean & \multirow{2}{*}{$\begin{array}{l}0 \cdot 3 \\
(0 \cdot 2-0 \cdot 6)\end{array}$} & \multirow{2}{*}{$\begin{array}{l}0.5 \\
(0 \cdot 2-0.8)\end{array}$} \\
\hline $\begin{array}{c}\text { Range } \\
\text { Index }\end{array}$ & & \\
\hline Mean & \multirow{2}{*}{$\begin{array}{l}200 \cdot 7 \\
(140 \cdot 48-280)\end{array}$} & \multirow{2}{*}{$\begin{array}{l}89 \cdot 75 \\
(39-200 \cdot 8)\end{array}$} \\
\hline Range & & \\
\hline
\end{tabular}

Table 3 Contrast sensitivity: contrast threshold(SD) at different spatial frequencies

\begin{tabular}{llll}
\hline $\begin{array}{l}\text { Spatial } \\
\text { frequency } \\
\text { (cycles/degree) }\end{array}$ & $\begin{array}{l}\text { Contrast } \\
\text { threshold (CTI) } \\
\text { group 1 }\end{array}$ & $\begin{array}{l}\text { Contrast } \\
\text { threshold (CT2) } \\
\text { group 2 }\end{array}$ & $\begin{array}{l}\text { Ratio } \\
\text { CT2/CT1 } \\
(\%)\end{array}$ \\
\hline $1 \cdot 5$ & $3 \cdot 1(1 \cdot 6-6 \cdot 3)$ & $2 \cdot 4(1-4)$ & 77 \\
3 & $2 \cdot 2(1-4)$ & $1 \cdot 3(0 \cdot 63-1 \cdot 6)$ & 60 \\
6 & $2 \cdot 7(0 \cdot 63-10)$ & $1(0 \cdot 63-1 \cdot 6)$ & 37 \\
12 & $6 \cdot 8(1 \cdot 6-20)$ & $3 \cdot 1(1-6 \cdot 3)$ & 45 \\
20 & $26 \cdot 2(6 \cdot 3-63)$ & $9 \cdot 5(2 \cdot 5-20)$ & 36 \\
\hline
\end{tabular}

\section{Results}

No significant difference was noted between the two age groups, the time period between the surgical procedure and examination, the mean astigmatism, and the surgical technique (Table 2).

\section{VISUAL ACUITY}

All selected patients had a best corrected visual acuity $\geqslant 8 / 10$ Parinaud 2 .

No significant difference was found for distant visual acuity between the two groups $(p=0 \cdot 12)$. For near vision, a significant difference in favour of monofocal IOLs was noted $(p=0.001)$ when monofocal IOLs with near vision correction and multifocal IOLs without near vision correction were compared. No significant difference was noted between the two groups with near vision correction.

In seven cases, a correction ranging from +0.50 to +1.25 dioptres was needed to improve near vision in group 1 ('multifocal).

\section{CONTRAST SENSITIVITY}

A statistical comparison between the two groups was made for each spatial frequency (SF) (Table 3). For each SF, a significant difference was noted:

SF $: 1.5$ cycles/degree $p=0.05 ; 3$ cycles/degree $\mathrm{p}=0.001 ; 6$ cycles/degree $\mathrm{p}=0.001 ; 12$ cycles/ degree $\mathrm{p}=0.002 ; 20$ cycles/degree $\mathrm{p}=0.0016$.

The difference was progressively more significant for $1 \cdot 5,12,20,3$, and 6 cycles/degree, respectively. This may be seen on the comparative curves of contrast sensitivity (Fig 1).

\section{DYNAMIC VISUAL ACUITY}

No significant difference was noted in photopic visual acuity ( $>8.1 \mathrm{LU}$ psb) between the two groups. On the other hand, a significant difference was found for mesopic visual acuity $(>5 \cdot 8-$ $<8 \mathrm{LU}, \mathrm{psb})$ between both groups $(\mathrm{p}=0.0015)$.

The index $(I=E \times D \times A)$ study showed a highly significant difference between both groups $\left(p<10^{-6}\right)$. The mean index $I$ is 37 for young people and 54 at 45 years. It was 200.7 in the multifocal group and 89.75 in the monofocal group (Table 2).

\section{Discussion}

For seven of the 19 eyes with multifocal IOLs, an additional correction was needed to reach a near visual acuity $\geqslant$ Parinaud 2 . This indicates that a partial loss of multifocal property was found in a high percentage $(36 \cdot 8 \%)$. Moreover, the multi- 
Figure 1 Comparative curves of monofocal and multifocal intraocular lenses. The zone between the 10 percentile curve and the 90 percentile curve indicates the range for a normal population. The 10 percentile, 50 percentile, and the 90 percentile curves represent the contrast sensitivity values for the 10 percentile, 50 percentile, and 90 percentile of a normal population, respectively.

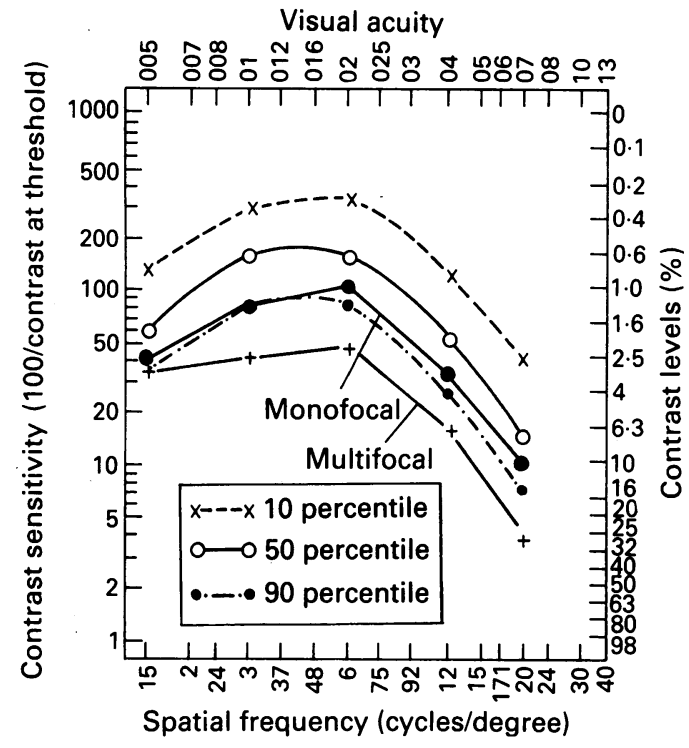

focal property was associated with a low contrast sensitivity.

The results of this study show the limitation of multifocal IOLs outside the standard condition of vision and confirm the concept of 'visual noise' mentioned by Nordmann. ${ }^{3}$ Olsen and Corydon's study $^{4}$ (13 eyes) and the European multicentric study (EMS) (56 eyes) did not find any difference in contrast sensitivity levels between the two types of IOLs. ${ }^{5}$

On the contrary, Nowack ${ }^{6}$ using the Ocutrast technique reported a significant loss of contrast sensitivity in the multifocal group compared with a monofocal group.

Bonnet et $a l,{ }^{7}$ using the Pelli-Robson ${ }^{8}$ and the Regan' tests, also found a significant difference.

Concerning DVA, to our knowledge no study with multifocal IOLs has been performed. On the other hand, our results confirm those of Bonnet et $a l$ who showed a change for distant and near visual acuity, as well as a lower contrast sensitivity with multifocal IOLs under low luminance.

DVA with index I measures visual performance under low illumination. As was stated earlier, this index depends on the adaptation time. The index was significantly higher in the multifocal IOLs group indicating that the adaptation time in dim luminance was superior and the visual performances under low luminance were lower in the multifocal group.

In other words, a person with a multifocal IOL would take longer to detect an object in a dim room, or would not detect it at all if a weak contrast existed between the object and the background.

HOW CAN THE DIFFERENCES IN PERFORMANCE BETWEEN MONOFOCAL AND MULTIFOCAL IOLS BE EXPLAINED?

The incident light crossing a multifocal IOL is divided into two beams, and only one of them is projected on to the retina. For diffractive IOLs, the division of light does not depend on pupil size, but $18 \%$ of the incident light is diffused away and is not focused on any focal plane. ${ }^{10}$

Multifocal IOLs are very sensitive to varia- tions in astigmatism and once the stabilisation of this factor occurs, there is a retinocortical adaptive benefit in low contrast sensitivity."

The decentration of the IOL plays a role in functional results and an 'in the bag' implantation is necessary. ${ }^{12}$

To benefit from the multifocal property, perfect biometric measurements are advisable, given that the slightest error during this procedure will alter the functional outcome.

\section{Conclusion}

Our comparison of multifocal/monofocal IOLs confirms the results of the most important studies for contrast sensitivity, particularly the clinical evaluation by the Food and Drug Administration of the $3 \mathrm{M}$ diffractive multifocal IOL in 671 patients with 1 year follow up. ${ }^{13}$ For dynamic visual acuity, index I gave a numbered value of the deterioration of visual function under low illumination, and confirmed the clinical impression published elsewhere. These data must be considered when selecting patients; multifocal IOLs should be reserved for patients with normal psychosensitive adaptation, particularly in the elderly. Moreover, the FDA requires the makers of multifocal IOLs to provide information on the following ${ }^{1+}$ :

static and dynamic acuity

perception of angular movement

movement in depth

visual field

fixation

glare sensitivity

colour vision

contrast sensitivity

adaptation

scotopic/mesopic vision

Finally, the presence of an ocular pathology (macular or other) that could alter contrast sensitivity or vision under low illumination, is a contraindication for multifocal IOLs.

1 Lagoutte F, Poirier L. Sensibilité au contraste. Coup d'Oeil Magazine 1991; 31.

2 Hamard H, Chevalereaud J, Rondot P. Neuropathies optiques. Rapport Soc Fr Ophtalmol. Masson, 1986.

3 Nordmann JP. Une nouvelle vision malgré un implant multifocal. F Fr Ophtalmol 1990; 13: 309-10.

4 Olsen T, Corydon L. Contrast sensitivity in patients with a new type of multifocal intraocular lens. $\mathcal{F}$ Cataract Refract new type of multifo

5 De Laage de Meux P. Résultats de l'étude multicentrique européenne (EMS). Communication Symposium Implant Multifocal diffractif, Paris, mai 1990.

6 Nowack MR. Expérience clinique et évaluation de la sensibilité au contraste avec la méthode Ocutrast. Communication Symposium Implant Multifocal Diffractif, Paris, mai 1990

7 Bonnet P, Robinet A, Colin J. Etude comparative de deux types d'implants bifocaux par la mesure de l'acuité visuelle et de la sensibilité au contraste. F Fr Ophtalmol 1991; 14: de la sen

8 Pelli DG, Robson JG, Wilkins AJ. The design of a new letter chart for measuring contrast sensitivity. Clin Vis Sci 1988; 2: 187-99.

9 Regan D, Neima D. Low contrast letter charts as a test of visual function. Ophthaimology 1983; 90: 1192-200.

10 Cornic JC. Indication chirurgicale et contrôle technique des implants multifocaux. Communication Symposium Implan Multifocal Diffractif, Paris, mai 1990.

11 Dublineau P. Implant multifocal diffractif, acuité visuelle et âge des patients. Communication au Congrès de la Soc $\mathrm{Fr}$ Ophtalmol, mai 1991.

12 Dublineau P. A propos de $\mathbf{4 0 0}$ cas d'implants multifocaux diffractifs en pratique courante. Communication Symposium Implant Multifical Diffractif, Paris, mai 1990.

13 Lindstrom RRL. Food and drug administration study update one year results from 671 patients with the $3 \mathrm{M}$ multifocal one year results from 671 patients with the $3 M$
intraocular lens. Ophthalmology 1993; 100: $91-7$. 14 Knaub J. FDA wants more multifocal IOL data. Ocular 